\title{
ASPECTOS AMBIENTAIS, PRODUTIVOS E ECONÔMICOS DO APROVEITAMENTO DE RESÍDUO UUMIDO DE CERVEJARIA NAALIMENTAÇÃO DE CORDEIROS EM SISTEMA DE CONFINAMENTO
}

\author{
Environmental, productive and economic aspects of use of brewery residue as \\ food of lamb feedlots in finishing phase
}

\author{
Mariana Augusta Brochier ${ }^{1}$, Sérgio Carvalho
}

\begin{abstract}
RESUMO
Objetivou-se com este trabalho avaliar a geração e o poder poluente do resíduo úmido de cervejaria e determinar aspectos produtivos e a economicidade do uso desse resíduo em substituição ao alimento concentrado na alimentação de cordeiros confinados em fase de terminação. Foram utilizados 25 cordeiros, machos, não-castrados, da raça Texel, oriundos de parto simples, desmamados aos 69 dias de idade em média. Foram avaliados cinco níveis de substituição do alimento concentrado por resíduo úmido de cervejaria, sendo $0 \%, 25 \%, 50 \%, 75 \%$ e $100 \%$. Os cordeiros foram abatidos, após um período experimental de 77 dias. Foram gerados 132,02 $\mathrm{kg}$ de resíduo úmido de cervejaria para cada $100 \mathrm{~kg}$ de grão de cevada utilizada como matéria-prima. O resíduo úmido de cervejaria foi classificado como Classe IIA e apresentou valores para $\mathrm{pH}$ de 4,63, para $\mathrm{DBO}_{5}$ de $659 \mathrm{mg} \mathrm{O}_{2} \mathrm{~L}^{-1}$ e para DQO de $10.769,9 \mathrm{mg} \mathrm{O}_{2} \mathrm{~L}^{-}$ ${ }^{1}$, revelando que o resíduo avaliado possui alta carga poluidora. Verificou-se efeito quadrático sobre o consumo de matéria seca e linear decrescente sobre o ganho de peso diário e o peso de carcaça fria com o aumento do nível de resíduo úmido de cervejaria. A análise econômica mostrou haver redução linear no custo da alimentação dos animais com o aumento da quantidade de resíduo de cervejaria nas dietas. Contudo, não foi verificado efeito do nível de inclusão do resíduo de cervejaria sobre o lucro relacionado à venda dos animais vivos ou à venda das carcaças.
\end{abstract}

Termos para indexação: Confinamento, meio ambiente, ovinos, resíduo de cervejaria.

\begin{abstract}
The objectives of this work were to evaluate the generation and the pollutant power of brewery residues and to determinate the productive and economic aspects of the use of this residue as replacement to the concentrate meal on the diet of lamb in feedlots as the finishing phase. Twenty-five male, non-castrated Texel lambs, single born, weaned at the age of 69 days were used. They were offered diets with five levels $(0 \%, 25 \%, 50 \%, 75 \%$, and $100 \%)$ of brewery residues replacing the meal concentrate. The lambs were slaughtered 77 days after the installation of the experiment. For every $100 \mathrm{~kg}$ barley grain used as source material, $132.02 \mathrm{~kg}$ of brewery residue was generated. The brewery residue was classified as Class IIA and showed $\mathrm{pH}$ value of 4.63 , for $\mathrm{BOD}_{5}$ of $659 \mathrm{mg}$ $\mathrm{O}_{2} \mathrm{~L}^{-1}$ and for COD of $10769.9 \mathrm{mg} \mathrm{O}_{2} \mathrm{~L}^{-1}$, revealing that this residue has high pollutant charge. There was a quadratic effect on the dry matter food intake and a decreasing linear effect on the daily weight gain and the cold carcass weight with the increase in the level of brewery residues. The economical analysis showed that there was a linear decrease in the feed costs with the increase of the quantity of brewery residues in the diets. However, no effect of the inclusion level of the brewery residues on the profit related to live animal or carcass sales was verified.
\end{abstract}

Index terms: Feedlot, environmental, sheep, brewery residue.

(Recebido em 30 de julho de 2008 e aprovado em 4 de maio de 2009)

\section{INTRODUÇÃO}

Da mesma forma que aconteceu com a indústria, a evolução do agronegócio e o desenvolvimento dos processos de transformação de alimentos levaram à geração de muitos resíduos, sendo que estes são um dos principais problemas ambientais, não só do Brasil, mas do mundo como um todo (Giordano, 2000).

Os resíduos gerados nos processos agroindustriais representam perdas econômicas no processo produtivo e, se não receberem destinação adequada, podem proporcionar problemas ambientais, em razão da sua carga poluidora. Dentre estes resíduos, existem vários que podem ser utilizados na alimentação de ruminantes, podendo ser citados, como exemplo, a polpa cítrica, a casca e o farelo de arroz, a torta de algodão e o resíduo úmido de cervejaria. Este último tem se destacado, uma vez que é gerado em grande volume durante o ano todo (Brochier, 2007).

O resíduo úmido de cervejaria é resultante da fase inicial do processo de fabricação de cervejas, e apresenta-

${ }^{1}$ Mestre em Gestão Tecnológica: Qualidade Ambiental. Centro Universitário Feevale - mariana.brochier@gmail.com

${ }^{2}$ Professor do Departamento de Zootecnia - Universidade Federal de Santa Maria - Avenida Roraima, no 1000, Bairro Camobi - Santa Maria, RS - $97105-900$ scarvalhoufsm@hotmail.com 
se na forma de cascas ou de farelo, com umidade em torno de $80 \%$. Segundo Fischer (1996) ${ }^{1}$, para cada $100 \mathrm{~kg}$ de malte de cevada que se utiliza para elaboração da cerveja, obtémse de 110 a $120 \mathrm{~kg}$ de resíduo úmido de cervejaria. O resíduo de cervejaria pode se apresentar na forma de resíduo úmido, resíduo prensado, resíduo seco e levedura de cerveja (Souza, 2005). Nas condições brasileiras, predomina a geração do resíduo úmido, uma vez que o processo de secagem é economicamente inviável.

Entre as alternativas para o aproveitamento de resíduos agroindustriais a alimentação animal tem um grande potencial, principalmente de ruminantes, que possuem capacidade de transformar resíduos de vegetais em nutrientes. Toda essa transformação se dá no rúmen, onde, pela ação de microorganismos, ocorre a fermentação da matéria-prima bruta consumida e a síntese de nutrientes assimiláveis pelo organismo (Silva Filho et al., 2001).

Nesse sentido, a utilização de resíduo úmido de cervejaria na ovinocultura de corte tem grande potencial, pois pode levar à queda significativa dos custos de produção e promover a redução de impactos ambientais, advindos da indústria cervejeira, sem que ocorram quedas nos índices produtivos.

Assim, neste trabalho, objetivou-se caracterizar a geração e a carga poluidora do resíduo úmido de cervejaria e avaliar alguns aspectos produtivos e a viabilidade econômica do aproveitamento desse resíduo na alimentação de cordeiros confinados em fase de terminação.

\section{MATERIAL E MÉTODOS}

$\mathrm{Na}$ fase inicial do experimento, realizou-se uma avaliação da geração do resíduo úmido de cervejaria, sendo que esta etapa foi desenvolvida no mês de outubro de 2005 na cervejaria Barley, localizada no município de Capela de Santana, RS. Foi realizado um acompanhamento da fase inicial do processo agroindustrial da produção de cerveja, que consta do beneficiamento da matéria-prima (limpeza e pesagem da cevada), mosturação (dissolução da cevada moída com água em tina de aço inox com o uso de diferentes rampas de temperatura, chegando a $76^{\circ} \mathrm{C}$ no final do processo) e filtração (separação das cascas de cevada do mosto).

Inicialmente, foi pesada toda a cevada utilizada no processo de fabricação, sendo tomadas amostras para realização de análises laboratoriais. Após um período de 7 horas, o mosto foi totalmente removido da tina de mosturação, restando apenas o resíduo úmido de cervejaria. Esse resíduo foi então retirado da tina, com auxílio de pá e um carrinho para coleta, e acondicionado em bombonas plásticas. As bombonas foram pesadas vazias e depois com o resíduo. A diferença entre as pesagens representa o peso do resíduo. Foi então coletada uma amostra composta para posterior classificação do resíduo úmido de cervejaria quanto aos seus riscos potenciais ao meio ambiente e à saúde pública, conforme descrito na NBR-10.004 (ABNT, 2004a), e procedimento de lixiviação de resíduo, conforme NBR-10.005 (ABNT, 2004b).

$\mathrm{Na}$ sua fase de ensaio de alimentação animal, o trabalho foi conduzido nas instalações de ovinocultura de uma propriedade rural situada no município de Capela de Santana, RS. O período experimental estendeu-se de 20 de outubro de 2005 a 04 de janeiro de 2006.

Foram utilizados 25 cordeiros, machos, não castrados, da raça Texel, nascidos de parto simples, desmamados aos 69 dias de idade, em média, com peso vivo médio de $14,38 \mathrm{~kg}$. Os animais foram distribuídos aleatoriamente em cinco tratamentos, com cinco repetições cada, tendo sido confinados em baias individuais, totalmente cobertas, com piso ripado e dimensão de $1,5 \mathrm{~m}^{2}$ por animal. Todas as baias eram providas de comedouros e bebedouros, onde foram fornecidos alimento e água para os animais.

Os tratamentos foram constituídos por diferentes níveis de substituição do alimento concentrado da dieta por resíduo úmido de cervejaria, sendo estes: $\mathrm{T} 1=0 \%$; $\mathrm{T} 2$ $=25 \% ; \mathrm{T} 3=50 \% ; \mathrm{T} 4=75 \%$ e T5 $=100 \%$ de substituição.

Após o desmame, os cordeiros foram mantidos em regime de confinamento, recebendo uma dieta composta de feno de Tifton- 85 e mistura concentrada em uma relação volumoso:concentrado de 40:60, com base na matéria seca (MS). O alimento concentrado foi constituído por milho desintegrado, farelo de soja, calcário calcítico e resíduo úmido de cervejaria, sendo que as proporções variaram de acordo com os tratamentos. As dietas foram formuladas para serem isoprotéicas, baseadas no teor de proteína bruta (PB) do tratamento com maior nível de resíduo. Na Tabela 1, é apresentada a composição química dos ingredientes utilizados na formulação das dietas e na Tabela 2, a proporção dos ingredientes utilizados na formulação das dietas e a composição química das dietas experimentais.

$\mathrm{O}$ alimento foi fornecido, ad libitum, duas vezes ao dia, sendo os horários de arraçoamento às $7 \mathrm{~h} 30$ e 17h30. A quantidade oferecida foi ajustada em função da sobra observada diariamente, sendo que esta deveria ser de $15 \%$ da quantidade oferecida no dia anterior, de modo a garantir o consumo voluntário máximo dos animais e manter o consumo da relação volumoso:concentrado de 40:60. Neste sentido, foram realizadas pesagens diárias das sobras e do alimento que foi oferecido pela manhã e pela tarde, para cada animal. 
Tabela 1 - Composição química em termos de matéria seca (MS), proteína bruta (PB), fibra em detergente neutro (FDN), energia líquida $(\mathrm{EL})$, cálcio $(\mathrm{Ca})$ e fósforo $(\mathrm{P})$, dos ingredientes utilizados na formulação das dietas experimentais.

\begin{tabular}{lccccc}
\hline & \multicolumn{3}{c}{ Ingredientes } \\
\cline { 2 - 5 } & $\begin{array}{c}\text { Feno de Tifton- } \\
85\end{array}$ & $\begin{array}{c}\text { Milho } \\
\text { desintegrado }\end{array}$ & Farelo de soja & $\begin{array}{c}\text { Resíduo de } \\
\text { cervejaria }\end{array}$ & Calcário calcítico \\
\hline MS (\%) & 78,10 & 84,20 & 82,70 & 22,60 & 100 \\
PB (\% MS) & 7,30 & 6,60 & 44,00 & 24,60 & ---- \\
FDN (\% MS) & 55,00 & 9,00 & 12,00 & 55,00 & ---- \\
EL (Mcal/kg) & 1,00 & 1,96 & 1,94 & 1,50 & $-34,00$ \\
Ca (\% MS) & 0,31 & 0,03 & 0,30 & 0,33 & 0,02 \\
P (\% MS) & 0,19 & 0,30 & 0,68 & 0,55 & \\
\hline
\end{tabular}

- Valor obtido em Ribeiro (1997).

Tabela 2 - Proporção dos ingredientes e composição química das dietas experimentais em termos de matéria seca (MS), proteína bruta (PB), fibra em detergente neutro (FDN), energia líquida (EL), cálcio (Ca) e fósforo (P).

\begin{tabular}{lccccc}
\hline & \multicolumn{5}{c}{ Nível de resíduo } \\
\cline { 2 - 5 } & 0 & 25 & 50 & 75 & 100 \\
\hline Feno de Tifton-85 & \multicolumn{5}{c}{ Proporção dos ingredientes (\%MS) } \\
Milho desintegrado & 40 & 40 & 40 & 40 & 40 \\
Farelo de soja & 30,42 & 22,71 & 15,01 & 7,31 & ---- \\
Resíduo de cervejaria & 28,62 & 21,39 & 14,16 & 6,93 & 59,33 \\
Calcário calcítico & ----- & 15,00 & 30,00 & 45,00 & 0,67 \\
& 0,96 & 0,90 & 0,83 & 0,76 & 45,32 \\
MS & & Composição química das dietas $(\% \mathrm{MS})$ & 17,52 \\
PB & 84,15 & 74,34 & 64,52 & 54,70 & 54,63 \\
FDN & 17,52 & 17,52 & 17,52 & 17,52 & 1,29 \\
EL (Mcal/kg) & 29,42 & 36,11 & 42,80 & 49,49 & 0,55 \\
Ca & 1,55 & 1,49 & 1,42 & 1,35 & 0,40 \\
P & 0,55 & 0,55 & 0,55 & 0,55 & 0,39 \\
\hline
\end{tabular}

${ }^{1}$ - Valor calculado a partir de Ribeiro (1997).

O período experimental foi precedido de um período de 14 dias para adaptação dos animais às instalações, manejo e alimentação, onde os animais receberam o mesmo tratamento do período experimental. O ensaio de alimentação iniciou após a fase de adaptação, estendendo-se por um período de 77 dias. Os cordeiros foram pesados no início e final da fase experimental, sendo que, para um melhor acompanhamento do desempenho, foram realizadas pesagens intermediárias a cada 14 dias. A última pesagem foi realizada com um intervalo de 21 dias.

A cada duas semanas foram coletadas amostras das sobras (15\% do peso total) e dos alimentos oferecidos, sendo feitas amostras compostas a cada 28 dias. Essas foram acondicionadas em sacos plásticos identificados e armazenadas em congelador a $-10^{\circ} \mathrm{C}$, para posteriores análises laboratoriais. As análises foram realizadas na Central Analítica do Centro Universitário Feevale, segundo as metodologias descritas em Silva (1998).

O abate ocorreu após um jejum de sólidos e líquidos com duração de 12 horas. Os cordeiros foram pesados e, em seguida, abatidos. Após cada abate, a carcaça foi pesada individualmente e, em seguida, resfriada por 18 horas em câmara frigorífica, a uma temperatura de $1^{\circ} \mathrm{C}$. Após este período, as carcaças foram novamente pesadas para obtenção do peso de carcaça fria. 
Para se efetuar a análise econômica da alimentação oferecida no experimento, foram considerados os preços de mercado obtidos na região do estudo para os ingredientes das rações, para a carcaça e peso vivo dos cordeiros. De posse do custo de cada ração e do consumo das mesmas, foi calculado o resultado econômico proporcionado por ração. Utilizou-se um valor de $\mathrm{R} \$ 3,50 / \mathrm{kg}$ de peso vivo dos cordeiros, $\mathrm{R} \$ 10,00 / \mathrm{kg}$ de carcaça, $\mathrm{R} \$ 0,35 / \mathrm{kg}$ de feno de Tifton- $85, \mathrm{R} \$ 0,52 / \mathrm{kg}$ de milho moído, $\mathrm{R} \$ 0,83 / \mathrm{kg}$ de farelo de soja, $\mathrm{R} \$ 0,07 / \mathrm{kg}$ de resíduo úmido de cervejaria e $\mathrm{R} \$ 0,02 / \mathrm{kg}$ de calcário calcítico.

$\mathrm{O}$ delineamento experimental utilizado foi o inteiramente casualizado com cinco tratamentos e cinco repetições, sendo cada cordeiro considerado uma unidade experimental. Os dados foram submetidos à análise de variância e de regressão pelo programa SAS Institute (1999). Os modelos foram selecionados com base nos coeficientes de determinação e na significância dos coeficientes de regressão, adotando-se o nível de $10 \%$ de probabilidade, utilizando-se o teste F.

\section{RESULTADOS E DISCUSSÃO}

A quantidade de cevada utilizada na produção de cerveja foi de $351,30 \mathrm{~kg}$ e a quantidade de resíduo úmido gerado dessa produção foi de 463,80 kg. Verifica-se que a quantidade de resíduo gerado, em kg, é 32,02\% superior à quantidade de cevada utilizada como matéria-prima inicial para produção de cerveja. Esse resultado é superior à afirmativa de Fischer (1996) ${ }^{3}$, de que para cada $100 \mathrm{~kg}$ de malte de cevada que se utiliza para elaboração de cerveja, obtém-se de 110 a $120 \mathrm{~kg}$ de resíduo úmido de cervejaria. No presente estudo, para cada $100 \mathrm{~kg}$ de matéria-prima utilizada, foi gerado 132,02 $\mathrm{kg}$ de resíduo úmido, o que demonstra o grande potencial gerador de resíduo da indústria cervejeira no Brasil.

Na Tabela 3, apresenta-se a classificação e as características químicas do resíduo úmido de cervejaria, demonstrando o seu potencial poluidor. A norma brasileira NBR-10.004 inclui em sua definição de resíduos sólidos todos aqueles resíduos no estado sólido e semi-sólido que resultam da atividade de origem industrial, doméstica, hospitalar, comercial, de serviços de varrição ou agrícola. Portanto, segundo essa definição, o resíduo úmido de cervejaria é classificado como sendo um resíduo sólido.

De acordo com Naime (2005), o gerenciamento inadequado e a disposição desconforme de resíduos sólidos constituem fatos geradores de poluição e crimes ambientais, sendo que a primeira providência para o gerenciamento adequado dos resíduos sólidos é a sua classificação.

Os critérios adotados para caracterizar resíduos são definidos em função da origem e de sua degradabilidade. Os

${ }^{3}$ FISCHER, C. Cervejaria BRAHMA, unidade de Santa Catarina, 1996. Comunicação pessoal. critérios não solucionam todos os problemas, mas são úteis para obtenção de uma classificação operacional. Assim, a partir do conjunto de regras e definições da NBR-10.004 o resíduo úmido de cervejaria pode ser classificado e enquadrado no grupo de Resíduos de Classe IIA (não inertes): são os resíduos que não se enquadram em nenhuma das outras classes (I e IIB), mas são reativos, e podem apresentar combustibilidade, biodegradabilidade ou solubilidade em água, estando incluídos a matéria orgânica, papéis, papelão, matéria vegetal e outros (Naime \& Garcia, 2004).

Deve-se considerar que, como os resíduos de atividades agroindustriais (aí incluídas atividades agropecuárias) apresentam, em geral, grande concentração de material orgânico, o seu lançamento em corpos hídricos pode proporcionar grande decréscimo na concentração de oxigênio dissolvido nesse meio, cuja magnitude depende da concentração de carga orgânica e da quantidade lançada, além da vazão do curso d'água receptor.

Segundo Matos (2005), além de possível contaminação direta, os maiores impactos provocados por resíduos sólidos orgânicos são decorrentes da fermentação do material, quando pode ocorrer a formação de ácidos orgânicos ("chorume" - líquido de elevada $\mathrm{DBO}_{5}$ e DQO formado com a degradação do material orgânico e a lixiviação de substâncias tóxicas) com geração de maus odores e diminuição do oxigênio dissolvido em águas superficiais. A produção de gases fétidos provoca desconforto aos seres humanos e animais, além de poder atrair vetores de doenças. O material orgânico é, também, habitat para proliferação de micro (bactérias, fungos, vírus, protozoários, etc.) e macro vetores (moscas, mosquitos, baratas e ratos).

Entre os principais indicadores de poluição orgânica, encontram-se a Demanda Bioquímica de Oxigênio $\left(\mathrm{DBO}_{5}\right)$ e a Demanda Química de Oxigênio (DQO). No presente estudo (Tabela 3), a análise do lixiviado gerado a partir do resíduo úmido de cervejaria apresentou um valor de DQO de 10.769,0 $\mathrm{mg} \mathrm{O}_{2} \mathrm{~L}^{-1}$ e para $\mathrm{DBO}_{5}$ de $659 \mathrm{mg} \mathrm{O}_{2} \mathrm{~L}^{-1}$, valores estes que se equivalem, por exemplo, a alguns resultados obtidos em dejetos de suínos, o qual é reconhecido como um resíduo com alto poder poluente. Portanto, a análise do resíduo úmido de cervejaria revela que o mesmo possui alta carga poluidora, fazendo-se necessário um adequado gerenciamento e/ou destinação do mesmo para que impactos ambientais relevantes não sejam ocasionados.

$\mathrm{Na}$ Tabela 4, apresenta-se a composição químicabromatológica da cevada e do resíduo úmido de cervejaria. Observa-se que o teor de umidade da cevada é de apenas $17,53 \%$, passando para 77,40\% no resíduo úmido gerado. Esse aspecto é explicado pela quantidade de água utilizada nesta fase inicial da produção de cerveja, onde foram adicionados 2.200 litros de água aos $351,3 \mathrm{~kg}$ de cevada. Já o teor protéico passou de $2,88 \%$ na cevada para $24,60 \%$ no resíduo, o que caracterizou este resíduo como um suplemento protéico de 
valor médio, de possível utilização em alimentação animal. Outra diferença acentuada observada na composição químicabromatológica da cevada e do resíduo úmido de cervejaria refere-se ao teor de fibra em detergente neutro (FDN), o qual teve um acréscimo de $200,03 \%$, passando de $20,08 \%$ na cevada para $60,92 \%$ no resíduo, o que é explicado pela maior proporção de casca e menor de amido no resíduo em relação ao grão de cevada. Esse é um aspecto importante do ponto de vista nutricional, pois, entre as alternativas utilizadas para destinação/ aproveitamento da grande quantidade gerada de resíduo úmido de cervejaria, encontra-se o setor de nutrição animal, principalmente o de ruminantes. É sabido que ruminantes apresentam uma capacidade máxima do rúmen para ingestão de fibra, sendo que alimentos com alto teor de FDN, como no caso do resíduo avaliado, podem levar a uma limitação física do consumo e, com isso, limitar o potencial produtivo.

$\mathrm{Na}$ Tabela 5, são apresentados os resultados relacionados ao consumo de nutrientes e ao ganho de peso dos animais. $\mathrm{O}$ consumo de MS foi influenciado $(\mathrm{P} \leq 0,05)$ pela proporção de substituição do alimento concentrado por resíduo úmido de cervejaria, isto é, o consumo apresentou comportamento quadrático. O máximo consumo de MS ocorreu quando se substituiu $31,1 \%$ do alimento concentrado por resíduo úmido de cervejaria, correspondendo ao consumo de $0,654 \mathrm{~kg} / \mathrm{dia}$. A redução do consumo pode ser explicada pelo aumento do teor de FDN nas dietas, promovendo regulação física do consumo, confirmando a afirmativa de Kozloski et al. (2006), de que o aumento da proporção de FDN diminui o consumo de alimento por cordeiros confinados.

Os consumos de MO, PB e FDN, expressos em kg/ dia, foram influenciados, significativamente, pela porcentagem de substituição do alimento concentrado por resíduo úmido de cervejaria, apresentando comportamento quadrático. Esses resultados foram influenciados pelos mesmos padrões de consumo observados para MS.

Quanto ao ganho de peso diário, observa-se que o mesmo diminuiu linearmente $(\mathrm{P} \leq 0,1)$ com o aumento do nível de substituição do alimento concentrado por resíduo úmido de cervejaria. A redução verificada no ganho de peso diário pode ser explicada pela redução no aporte energético das dietas que ocorreu com a elevação do nível de substituição do concentrado por resíduo úmido de cervejaria, e pela redução no consumo de matéria seca (a partir de uma proporção de $31,1 \%$ de FDN na dieta) e, consequentemente, de energia líquida. Esse resultado é corroborado por Pires et al. (2006), os quais, trabalhando com 20 cordeiros confinados Ile de France x Texel alimentados com dietas contendo diferentes níveis de FDN $(25 \%, 31 \%$, 37\% e $43 \%$ ), observaram que o aumento do teor de fibra na dieta dos cordeiros promoveu redução linear no ganho de peso médio diário, resultado semelhante ao obtido no presente trabalho. Ganhos de pesos inferiores para dietas com menor aporte energético também foram observados por Dantas et al. (2008), os quais trabalharam com ovinos da raça Santa Inês terminados em condição de pastejo com diferentes níveis de suplementação, e verificaram diminuição do ganho de peso com a redução da suplementação e da concentração de energia na alimentação dos animais.

$\mathrm{Na}$ Tabela 6, são apresentados os resultados referentes à análise econômica do experimento realizado. Essa análise visou a avaliar apenas a viabilidade econômica da substituição do alimento concentrado por resíduo úmido de cervejaria na alimentação de cordeiros confinados em fase de terminação. Portanto, não foram considerados para a análise os custos fixos e operacionais relativos à mão-de-obra, sanidade e despesas diversas. Na realização do cálculo, utilizou-se a quantidade oferecida de alimento e, portanto, foram consideradas as sobras.

Tabela 3 - Classificação e composição química do resíduo úmido de cervejaria quanto a demanda bioquímica de oxigênio $\left(\mathrm{DBO}_{5}\right)$ e demanda química de oxigênio (DQO).

\begin{tabular}{lc}
\hline & Resíduo Úmido de Cervejaria \\
\hline Classe & IIA \\
pH do lixiviado & 4,63 \\
$\mathrm{DBO}_{5}\left(\mathrm{mg} \mathrm{O}_{2} \mathrm{~L}^{-1}\right)$ & 659 \\
$\mathrm{DQO}\left(\mathrm{mg} \mathrm{O}_{2} \mathrm{~L}^{-1}\right)$ & $10.769,9$ \\
\hline
\end{tabular}

Tabela 4 - Composição química-bromatológica da cevada e do resíduo úmido de cervejaria ${ }^{1}$.

\begin{tabular}{lcc} 
& Cevada & Resíduo Úmido \\
\hline Matéria Seca (\%) & 82,47 & 22,60 \\
Proteína Bruta (\% da MS) & 2,88 & 24,60 \\
Extrato Etéreo (\% da MS) & 10,13 & 8,42 \\
Fibra Detergente Neutro (\% da MS) & 20,08 & 60,92 \\
Cinzas (\% da MS) & 2,16 & 3,25 \\
\hline
\end{tabular}

${ }^{1}$ - Análises realizadas na Central Analítica do Centro Universitário Feevale. 
Tabela 5 - Valores médios para consumos de matéria seca (CMS), matéria orgânica (CMO), proteína bruta (CPB) e fibra em detergente neutro (CFDN), peso vivo inicial (PI), peso vivo final (PF) e ganho de peso diário (GPD), em função da proporção de substituição do alimento concentrado por resíduo úmido de cervejaria.

\begin{tabular}{lcccccccc}
\hline & \multicolumn{9}{c}{ Nível de resíduo } & & Equação de & CV \\
Itens & 0 & 25 & 50 & 75 & 100 & & Regressão & $(\%)$ \\
\hline CMS & 0,631 & 0,648 & 0,642 & 0,610 & 0,528 & & 1 & 11,95 \\
CMO & 0,591 & 0,606 & 0,603 & 0,575 & 0,501 & & 2 & 12,94 \\
CPB & 0,118 & 0,120 & 0,120 & 0,114 & 0,100 & & 3 & 12,38 \\
CFDN & 0,262 & 0,314 & 0,359 & 0,382 & 0,367 & & 4 & 13,46 \\
PI & 16,16 & 16,77 & 15,82 & 15,82 & 14,66 & & Y $=15,81$ & 23,27 \\
PF & 28,00 & 28,20 & 26,80 & 28,48 & 22,12 & & Y = 26,66 & 20,71 \\
GPD & 0,153 & 0,148 & 0,142 & 0,164 & 0,097 & & 5 & 26,92 \\
\hline
\end{tabular}

1. $\hat{Y}=0,62886+0,00161 * * \operatorname{RES}-0,0000259 * * R_{E S}{ }^{2}, R^{2}=0,26$;

2. $\hat{Y}=0,58830+0,00149 * * R E S-0,00002341^{* *} R_{E} S^{2}, R^{2}=0,24$;

3. $\hat{Y}=0,11782+0,000278 * * R E S-0,00000452 * * R^{2} S^{2}, R^{2}=0,26$

4. $\hat{\mathbf{Y}}=\hat{\mathbf{Y}}=0,25960+0,00289 * * \operatorname{RES}-0,00001787 * * * \mathrm{RES}^{2}, \mathbf{R}^{2}=0,52$

5. $\hat{Y}=0,16085-0,00039047 * \operatorname{RES}, \mathbf{R}^{2}=0,13$;

6. $\hat{Y}=13,65020-0,03531^{* *} \operatorname{RES}, R^{2}=0,19$;

*, ** e $* * *$, significativo a 10,5 e $1 \%$ de probabilidade, respectivamente, pelo teste $\mathrm{F}$.

RES = nível de resíduo de cervejaria nas dietas.

Tabela 6 - Valores médios para peso vivo final (PF) e peso de carcaça fria (PCF) em kg, oferecido de matéria natural de feno (OFMNF), oferecido de matéria natural de concentrado (OFMNC) e oferecido de matéria natural de resíduo úmido de cervejaria (OFMNR), em kg/dia, custo diário de feno (CF), custo diário de concentrado (CCD), custo diário de resíduo úmido de cervejaria (CRD) e custo diário total (CDT), em R \$/animal/dia, custo total (CTotal), em R $\$$, receita do peso vivo (RPV), receita de carcaça (RC), lucro de peso vivo (LPV) e lucro de carcaça (LC), em R\$/animal, em função dos níveis de substituição do alimento concentrado por resíduo úmido de cervejaria.

\begin{tabular}{|c|c|c|c|c|c|c|c|}
\hline \multirow[b]{2}{*}{ Itens } & \multicolumn{5}{|c|}{ Nível de resíduo } & \multirow{2}{*}{$\begin{array}{c}\text { Equação de } \\
\text { Regressão }\end{array}$} & \multirow{2}{*}{$\begin{array}{l}\mathrm{CV} \\
(\%)\end{array}$} \\
\hline & 0 & 25 & 50 & 75 & 100 & & \\
\hline $\mathrm{PF}$ & 28,00 & 28,20 & 26,80 & 28,48 & 22,12 & $Y=26,66$ & 20,71 \\
\hline PCF & 12,98 & 13,22 & 11,98 & 12,42 & 8,92 & 1 & 23,29 \\
\hline OFMNF & 0,387 & 0,390 & 0,402 & 0,390 & 0,341 & 2 & 12,03 \\
\hline OFMNC & 0,542 & 0,410 & 0,281 & 0,136 & 0,0 & 3 & 15,16 \\
\hline OFMNR & 0,0 & 0,506 & 1,049 & 1,515 & 1,749 & 4 & 15,67 \\
\hline CFD & 0,14 & 0,14 & 0,14 & 0,14 & 0,12 & $Y=0,134$ & 11,99 \\
\hline $\mathrm{CCD}$ & 0,36 & 0,27 & 0,18 & 0,09 & 0,0 & 5 & 15,23 \\
\hline CRD & 0,0 & 0,03 & 0,07 & 0,10 & 0,12 & 6 & 15,81 \\
\hline $\mathrm{CDT}$ & 0,49 & 0,44 & 0,40 & 0,33 & 0,24 & 7 & 12,33 \\
\hline CTotal & 37,96 & 34,07 & 30,45 & 25,23 & 18,49 & 8 & 12,35 \\
\hline RPV & 98,00 & 98,70 & 93,80 & 99,68 & 77,42 & $Y=93,30$ & 20,72 \\
\hline $\mathrm{RC}$ & 129,77 & 132,19 & 119,74 & 124,16 & 89,20 & 9 & 23,29 \\
\hline LPV & 60,04 & 64,62 & 63,35 & 74,45 & 58,93 & $Y=64,26$ & 25,05 \\
\hline $\mathrm{LC}$ & 91,81 & 98,11 & 89,29 & 98,93 & 70,71 & $Y=89,42$ & 28,16 \\
\hline
\end{tabular}

1. $\hat{\mathrm{Y}}=13,65020-0,03531 * * \mathrm{RES}, \mathrm{R}^{2}=0,19$;

2. $\hat{Y}=0,38308+0,00109 * R E S-0,00001470 * R_{E S}^{2}, R^{2}=0,20$;

3. $\hat{\mathrm{Y}}-0,54524-0,00543 * * * R E S, \mathrm{R}^{2}-0,96$

4. $\hat{\mathrm{Y}}=0,06292+0,01802 * * * \mathrm{RES}, \mathrm{R}^{2}=0,95$

5. $\hat{\mathrm{Y}}=0,35923-0,00359 * * * \mathrm{RES}, \mathrm{R}^{2}=0,96$

6. $\hat{\mathrm{Y}}=0,00444+0,00124 * * * \mathrm{RFS}, \mathrm{R}^{2}=0,95$

7. $\hat{\mathrm{Y}}=0,50382-0,00248 * * * \mathrm{RES}, \mathrm{R}^{2}=0,80$

8. $\hat{Y}=38,79269-0,19108 * * * R E S, R^{2}=0,80$;

9. $\hat{Y}=136,48251-0,35305 * * R E S, R^{2}=0,19$.

$*$,** $\mathrm{e} * * *$, significativo a 10,5 e $1 \%$ de probabilidade, respectivamente, pelo teste $\mathrm{F}$;

RES $=$ nível de resíduo úmido de cervejaria nas dietas. 
Com relação aos alimentos oferecidos, o feno apresentou comportamento quadrático, o oferecido de concentrado diminuiu linearmente e o oferecido de resíduo apresentou comportamento crescente, conforme o aumento da proporção de substituição do alimento concentrado por resíduo úmido de cervejaria. Como consequência, o custo diário do feno não diferiu significativamente entre tratamentos, contudo, os custos diário e total com alimentação, decresceram com a substituição.

Em função do peso vivo final médio $(26,66 \mathrm{~kg})$ não ter diferido estatisticamente entre os tratamentos $(\mathrm{P}=0,16)$, a receita bruta relacionada à venda dos cordeiros vivos também não diferiu entre os tratamentos ( $\mathrm{R} \$ 93,30 \mathrm{em}$ média).

A receita bruta em relação ao peso de carcaça diminui linearmente com a elevação do teor de resíduo úmido de cervejaria na dieta, como consequência da redução do peso de carcaça fria. Contudo, quando se desconta da receita bruta a despesa total com alimentação (feno + concentrado + resíduo), verifica-se que, em razão da diminuição do custo de alimentação com a elevação do teor de resíduo úmido de cervejaria, quando se avaliou a lucratividade com relação à venda dos cordeiros vivos e das carcaças, não houve efeito significativo de tratamento, tendo sido encontrado um valor médio para lucratividade do peso vivo e da carcaça de $\mathrm{R} \$ 64,26$ e $\mathrm{R} \$ 89,42$, respectivamente.

\section{CONCLUSÕES}

A quantidade gerada de resíduo úmido de cervejaria é $32,02 \%$ superior à quantidade de cevada utilizada durante o processo inicial da produção de cerveja, o que caracteriza o setor cervejeiro como um grande gerador de resíduos. Além disso, os valores de $\mathrm{DBO}_{5}$ e de DQO presentes no lixiviado gerado a partir do resíduo úmido de cervejaria são elevados, o que indica o seu alto poder poluente e explicita a necessidade de uma adequada destinação para este resíduo, a fim de que passivos ambientais sejam evitados. Recomenda-se que a proporção máxima de substituição do alimento concentrado por resíduo úmido de cervejaria não ultrapasse $31,1 \%$, uma vez que níveis de substituição acima desse valor promovem regulação física do consumo de matéria seca, em razão do aumento da concentração de fibra em detergente neutro nas dietas, o que leva à redução do ganho de peso dos animais. O aumento do nível de resíduo de cervejaria na dieta de cordeiros em confinamento leva a redução do custo da alimentação dos animais.
Contudo, não há efeito do nível de inclusão do resíduo de cervejaria sobre o lucro relacionado à venda dos animais vivos ou à venda das suas carcaças. $O$ aproveitamento do resíduo úmido de cervejaria na alimentação de cordeiros da raça Texel em fase de terminação é uma alternativa para destinação adequada desse resíduo, porém, carece de mais estudos.

\section{REFERÊNCIAS BIBLIOGRÁFICAS}

ASSOCIAÇÃO BRASILEIRA DE NORMAS TÉCNICAS. NBR 10.004: resíduos sólidos: classificação. Rio de Janeiro, 2004a. 71p.

ASSOCIAÇÃO BRASILEIRA DE NORMAS TÉCNICAS. NBR 10.005: procedimento para obtenção de extrato lixiviado de resíduos sólidos. Rio de Janeiro, 2004b. 15p.

BROCHIER, M.A. Aproveitamento de resíduo úmido de cervejaria na alimentação de cordeiros confinados em fase de terminação. 2007. 120f. Dissertação (Mestrado em Qualidade Ambiental)-Centro Universitário Feevale, Novo Hamburgo, 2007.

DANTAS, A. F.; PEREIRA FILHO, J. M.; SILVA, A. M. de A.; SANTOS, E. M. dos; SOUSA, B.B.; CÉZAR, M.F. Características da carcaça de ovinos Santa Inês terminados em pastejo e submetidos a diferentes níveis de suplementação. Ciência e Agrotecnologia, Lavras, v.32, n.4, p.1280-1286, jul./ago., 2008.

GIORDANO, S.R. Gestão ambiental no sistema agroindustrial. In: ZYLBERSZTAJN, D.; NEVES, M.F. (Orgs.). Economia e gestão de negócios agroalimentares: indústria de alimentos, indústria de insumos, produção agropecuária, distribuição. São Paulo: Pioneira, 2000. p.255-281.

KOZLOSKI, G.V.; TREVISAN, L.M.; BONNECARRÈRE, L.M.; HÄRTER, C.J.; FIORENTINI, G.; GALVANI, D.B.; PIRES, C.C. Níveis de fibra em detergente neutro na dieta de cordeiros: consumo, digestibilidade e fermentação ruminal. Arquivo Brasileiro de Medicina Veterinária e Zootecnia, Belo Horizonte, v.58, n.5, p.893-900, 2006.

MATOS, A.T. Tratamento de resíduos agroindustriais. In: CURSO SOBRE TRATAMENTO DE RESÍDUOS AGROINDUSTRIAIS, 2005, Viçosa, MG. Anais... Viçosa, MG: Fundação Estadual do Meio Ambiente, 2005. p.1-34. 
NAIME, R.; GARCIA, A.C.A. Percepção ambiental e diretrizes para compreender a questão do meio ambiente. Novo Hamburgo: FEEVALE, 2004. 136p.

NAIME, R. Gestão de resíduos sólidos: uma abordagem prática. Novo Hamburgo: FEEVALE, 2005. 103p.

PIRES, C.C.; GALVANI, D.B.; CARVALHO, S.;

CARDOSO, A.R.; GASPERIN, B.G. Características da carcaça de cordeiros alimentados com dietas contendo diferentes níveis de fibra em detergente neutro. Revista Brasileira de Zootecnia, Viçosa, v.35, n.5, p.2058-2065, 2006.

RIBEIRO, S.D.A. Caprinocultura: criação racional de caprinos. São Paulo: Nobel, 1997. 318p.
SAS INSTITUTE. Statistical Analysis System: user's guide. Version 6.11. Washington, DC, 1999. 842p.

SILVA, D.J. Análise de alimentos: métodos químicos e biológicos. Viçosa, MG: UFV, 1998. 165p.

SILVA FILHO, J.C.; ARMELIN, M.J.A.; SILVA, A.G. Determinação da composição mineral de subprodutos agroindustriais utilizados na alimentação animal pela técnica de ativação neutrônica. Pesquisa

Agropecuária Brasileira, Brasília, v.34, n.2, p.235-241, 2001.

SOUZA, A.A. Resíduos de cervejaria na nutrição de bovinos de corte. Disponível em: <http:// 'WWW.beefpoint.com.br $>$. Acesso em: 13 abr. 2005. 